\title{
Adjustment of College Freshmen as Predicted by Both Perceived Parenting Style and the Five Factor Model of Personality
}

\author{
- Personality and Adjustment
}

\author{
Jennifer Schnuck, Paul J. Handal \\ Psychology Department, Saint Louis University, St. Louis, USA. \\ Email: jschnuck@slu.edu \\ Received March $6^{\text {th }}, 2011$; revised April 10 $0^{\text {th }}, 2011$; accepted May $12^{\text {th }}, 2011$.
}

\begin{abstract}
The adjustment that freshmen make to college is important, and is related to student retention. The present study explored the relationships among freshmen students' personality traits, their perceptions of the parenting styles employed by their mothers and fathers, their positive and negative adjustment, and their adaptation to college. Freshmen participants (74 men, 116 women) were from a Midwestern, religiously affiliated university. Results revealed that the relationships between parenting styles and adjustment to college, although statistically significant, were quite weak. In contrast, analyses revealed that strong relationships exist between personality traits and the adjustment that freshmen students make to college. These relationships were found to be different with regard to gender. The results have important implications for the adjustment that freshmen students make to college.

Keywords: Personality Traits, Parenting Styles, Adjustment to College
\end{abstract}

\section{Introduction}

The transition that students make from high school to college is important and relevant in regard to student retention. According to the National Center for Education Statistics (2003), $55 \%$ of students who begin their education at a 4 -year institution complete their bachelor's degree within 6 years at the institution in which they first enrolled. When individuals who transfer schools at some point during their undergraduate work are included, this rate increases to $63 \%$. However, this still leaves a significant number of individuals who do not complete their bachelor's degree. Studies have suggested that when students withdraw from universities it is often for personal reasons, including adjustment to college (Toews \& Yazedjian, 2007).

Of concern to college administrators is how to retain the students who enroll at their institution, and what factors might determine if students complete their degree. Parenting style and the personality traits of students are two factors that have been investigated with regard to the overall adjustment of college students. The present study explored the relationships among freshmen students' personality traits, their perceptions of the parenting styles employed by their mothers and fathers, their positive and negative adjustment, and their adaptation to college.

Previous studies have been devoted to exploring different parenting styles and the related outcomes for children, as specific parenting styles have been associated with children's levels of well-being (Lamborn, Mounts, Steinberg, \& Dornbusch, 1991). Diana Baumrind spearheaded research on control within different parenting styles, and is responsible for the most widely-used and accepted conceptualization of parenting styles (Hickman, Bartholomae, \& McKenry, 2000). She outlined three dimensions of control in parenting: authoritarian, authoritative, and permissive (Baumrind, 1968). Authoritarian parents attempt to shape and control their children's behaviors and attitudes to fit with a set standard of appropriate conduct. These parents value obedience and believe their children should value authority and obey without question. Baumrind (1968) conceptualized permissive parents as exerting insufficient control over their children. These parents allow their children to regulate their own activities. Authoritative parents attempt to direct their children's behaviors, but in a more evaluative way than authoritarian parents. They encourage discussion, and explanations for rules and reasoning are discussed with the children. Authoritative parents value both autonomy and conformity, and strive for a healthy balance. An authoritative parenting style has consistently been identified as having the best influence on children across many dimensions. For example, authoritative parenting is related to children's achievement, social development, mental health and self-esteem (Lamborn et al., 1991) as well as higher life-satisfaction and lower scores on a depression scale (Milevsky, Schlechter, \& Netter, 2007). Simons and Conger (2007) investigated parenting styles between mothers and fathers in two-parent families and found that having two authoritative parents was associated with the best outcome for adolescents (lowest levels of depression and greatest commitment to school), though even having just one authoritative parent seemed to buffer the adolescent against negative consequences.

While most studies have examined the effects of parenting style on high school adolescents and younger children, some studies have investigated the presence of a relationship between perceived parenting style and adjustment to college. Students who perceived their parents to use a predominantly authoritative parenting style were found to have greater academic ad- 
justment in a college setting (Hickman, Bartholomae, \& McKenry, 2000) and reported higher physical well-being and higher psychological well-being (Slicker \& Thornberry, 2002) when compared to students with more permissive or authoritarian parenting styles.

While parenting styles have been demonstrated to be related to the well-being of their offspring, some studies have investigated the effect that parenting styles have on the personality traits of their children (Baldwin, McIntyre, \& Hardaway, 2007; Heaven \& Ciarrochi, 2008). The studies suggested that an authoritative parenting style may be related to positive personality traits, including optimism and conscientiousness. Despite these findings, little research has investigated the relationship between perceived parenting style and personality as measured by the five factor model of personality.

The Big Five trait model of personality seems to be the most commonly used and agreed-upon conceptualization of personality (Bardi \& Ryff, 2007). A plethora of research has been conducted on the five factor personality model and various constructs, including subjective well-being (Costa \& McCrae, 1980; DeNeve \& Cooper, 1998). Extraversion and Neuroticism have been consistently linked to adjustment and well-being (Bardi \& Ryff, 2007), with Extraversion related to positive affect and Neuroticism linked to negative affect (Costa \& McCrae, 1980). Studies have also examined the relationship between personality and the academic achievement of college students, with findings that Conscientiousness is correlated with achievement in college as measured by GPA $(r=.26$ to .42; e.g., Wagerman \& Funder, 2007; Zyphur, Bradley, Landis, \& Thoresen, 2008).

A previous study in Canada investigated the possibility that both personality and reported parenting styles are related to adjustment to college in a sample of largely non-traditional freshmen living at home (Wintre \& Sugar, 2000). The authors reported correlations separately for men and women as well as for maternal and paternal parenting styles. They reported low but significant correlations between parenting styles and aspects of college adjustment. With regard to the Big Five personality factors, each of the five factors was correlated with multiple types of adjustment (ranging from $r=-0.68$ to $r=$ 0.59), with Openness to Experience correlating with the fewest adjustment variables (Wintre \& Sugar, 2000).

Recent findings revealed that there is a significant, albeit, low relationship between parenting style and college adjustment, and what appears to be preliminary findings regarding some correlations between aspects of parenting style and personality traits. In light of these findings, the present study was designed to more systematically investigate each relationship between and among parenting style, personality traits, and positive and negative adjustment to college. More specifically, there were three foci of the present study: to investigate the relationship between parenting styles and adjustment to college, to investigate the relationship between personality traits and adjustment, and to investigate the possibility that personality traits mediate the relationship between parenting style and adjustment to college.

The purpose of this study was to determine if several factors are related to college adjustment. First, is perceived parenting style related to the adjustment of college freshmen? Second, are personality traits related to the adjustment of college students?
Third, is perceived parenting style related to the personality traits of college freshmen as measured by the NEO-FFI? And finally, if a relationship does indeed exist between parenting style and adjustment, is the relationship mediated by personality?

It was hypothesized that parenting style would be related to level of adjustment; more specifically that an authoritative parenting style would be positively associated with the best overall adjustment to college. It was predicted that personality would also be associated with adjustment to college, with Extraversion and Openness to Experience positively associated with social adjustment, Conscientiousness positively associated with academic adjustment, and Neuroticism associated with poor social and personal-emotional adjustment.

It was also hypothesized that parenting style would be related to students' personality traits; more specifically that authoritarian parenting would be positively correlated with Neuroticism, and authoritative parenting would be positively related to Extraversion. Furthermore, it was hypothesized that personality traits would mediate the relationships between parenting style and adjustment to college. More specifically, it was hypothesized that relationships between parenting styles and adjustment to college, if mediated by personality traits, would no longer be significant when personality was accounted for in the model.

\section{Methodology}

\section{Participants}

The participants consisted of 190 freshmen students (74 men, 116 women) in their first semester of college. Participants identified as being either $18(77 \%)$ or 19 -years-old (23\%). Twenty percent of the participants reported that they were first-generation college students. The majority of participants were Caucasian $(82.5 \%)$ with married $(73.2 \%)$ and well-educated parents (66.6\% of participants' mothers and $70.1 \%$ of fathers were college graduates). Five (2.6\%) students identified as African American, 9.5\% identified as Asian American, 3.7\% were Hispanic, . $5 \%$ was Native American, and $1.1 \%$ of students indicated being of an ethnicity that was not listed among the response choices. In addition, the majority of the sample reported living in a dormitory (84.2\%), with $11.6 \%$ living in a house, and $3.7 \%$ living in an apartment. Most of the students resided with at least one other roommate who they either knew (21.6\%) or did not know before beginning college $(62.6 \%)$, while $15.3 \%$ reported living with their parents or another family member, and only one student $(0.5 \%)$ reported living alone.

\section{Materials}

The Parental Authority Questionnaire (PAQ) was used to measure students' perceptions of the parenting styles used by both their mothers and fathers. The PAQ consists of 30 items per parent, and yields measures of authoritarian, authoritative, and permissive parenting styles. Each item is associated with 1 of the 3 styles of parenting, and is rated on a 5-point scale by participants, where 1 equals "strongly disagree" and 5 equals "strongly agree." According to the developer of the PAQ (Buri, 1991), the test-retest reliability for the 3 different parenting style prototypes for both mothers and fathers ranges from .77 
to .92 . The Cronbach alphas for internal consistency for each of the 6 scales range from .74 to .87 (Buri, 1991). The scales were also demonstrated to have good discriminant-related validity, criterion-related validity, and do not seem to be vulnerable to social desirability response bias (Buri, 1991).

To assess for the students' adjustment to college, the Student Adaptation to College Questionnaire (SACQ; Baker \& Siryk, 1999) was administered. The SACQ is a self-report measure consisting of 67 items that are ranked by participants on a 9-point scale. The measure is used by colleges throughout the country to increase student retention rate; and it was standardized on over 1,300 college freshmen and stratified by semester of attendance (Baker \& Siryk, 1999). The SACQ yields a full scale score, and also assesses 4 different areas of adjustment including: academic adjustment, personal-emotional adjustment, social adjustment, and attachment to the institution. The reliability of the SACQ is quite good, with coefficient alpha values ranging from .77 to .86 for the personal-emotional adjustment scale up to .92 to .95 for the full scale (Dahmus \& Bernardin, 1992). The criterion-related or construct validity has also been demonstrated to be quite good, with the academic adjustment scale related to student grade point average ( $r=.17$ to .53$)$, the personal-emotional adjustment scale negatively correlated with seeking psychological services $(r=-.23$ to -.34$)$, and attachment to institution negatively correlated with attrition $(r=-.27$ to -.41 ; Baker \& Siryk, 1999).

To further assess for psychological adjustment, the Langner Symptom Survey (LSS; Langner, 1962) was administered as well. The LSS is a 22-item, epidemiological screening measure to assess for the presence of psychological and psychosomatic symptoms (Langner, 1962). The items chosen were selected because they clearly distinguish between out-patient psychiatric patients and non-ill individuals. The LSS items are scored with either a 0 (symptom is not present) or a 1 (symptom is endorsed), and therefore scores can range from 0 to 22. For each item, the response choices are: Yes, No, Don't Know, and Not Applicable. According to Langner (1962), a score of 4 or higher may be used as a cutting point to classify those individuals who are impaired versus not, as it accurately did for $84.4 \%$ of those considered "incapacitated" in the original study. However, the scale may also be used as a rough indication of where people lie on a continuum of impairment (Langner, 1962), and for the purpose of this study it was treated as a dimensional measure. The scores from the SACQ and LSS were used to assess the overall adjustment of college students.

An additional measure of psychological adjustment was used to investigate the subjective well-being of each participant. The Satisfaction with Life Scale (SWLS; Diener, Emmons, Larsen, \& Griffin, 1985), a brief, widely used self-report measure of satisfaction with life, was administered in order to assess for this area of adjustment and functioning. The SWLS consists of 5 items scored on a Likert scale, with response choices ranging from 1 (strongly disagree) to 7 (strongly agree). Higher scores on the SWLS are indicative of higher subjective well being, as well as a greater degree of happiness and satisfaction with life. In a study conducted by Diener et al., (1985), a mean SWLS score for college students was reported to be 23.5 , with a standard deviation of 6.4 and a coefficient alpha of .87 .

The NEO Five-Factor Inventory (NEO-FFI; Costa \& McCrae, 1992) was used to measure the personality of each student as measured by the five factor model of personality. The NEO-FFI is a 60-item short-form of the NEO Personality Inventory (NEO-PI-R; Costa \& McCrae, 1992), and consists of the Big Five trait dimensions of personality: Neuroticism, Extraversion, Openness to Experience, Conscientiousness, and Agreeableness. Each domain is measured by 12 items which are answered on a 5-point scale (Costa \& McCrae, 1992). The NEO-FFI is one of the most widely-used instruments to assess for personality (Bardi \& Ryff, 2007) and has demonstrated excellent psychometric properties, including: correlations from .77 to .92 with the NEO-PI-R domain scales, internal consistency coefficients ranging from .73 to .86 for the 5 domains, and evidenced convergent and discriminant validity (Costa \& McCrae, 1992).

A demographic questionnaire was also administered. The form includes items pertaining to the students' gender, age, year in school, ethnicity, parental marital status, and number of siblings. Additional questions also addressed if the students were first generation college students, where they lived (home, dorm, apartment, other), if they lived alone or with roommates, and if they lived at home with their parents, if this was their choice.

\section{Design and Procedure}

College freshmen were recruited to participate in the study through Sona, a website designed to recruit participants and facilitate experiments. Participants consented and completed the surveys online through Sona during the second half of the fall semester. Extra credit was granted for their participation.

\section{Results}

\section{Sample Characteristics}

In order to determine if gender differences existed among perceived parenting styles, a Multivariate Analysis of Variance (MANOVA) was conducted. A significant MANOVA $F$ was obtained, $F(6,171)=2.75, p<.05$, indicating a gender difference with regard to perceived parenting styles. In order to determine which parenting variables differed by gender, univariate $F$ statistics were calculated. Tests of between-subjects effects indicated that significant gender differences were present with regard to mother permissiveness $[F(1,176)=9.17, p<.01]$ and father permissiveness $[F(1,176)=6.53, p<.05]$. In both cases, men reported that their parents were more permissive than women did.

In order to determine if gender differences existed among personality variables, a second MANOVA was conducted. The MANOVA was found to be non-significant, indicating that there were no gender differences with regard to personality traits, $F(5,184)=1.76, p=.12$.

A third MANOVA was conducted in order to determine if gender differences existed among the adjustment variables, including the SACQ scales, the LSS, and the SWLS. A significant MANOVA was obtained, $F(7,161)=7.00, p<.001$, indicating that men and women responded differently on measures of adjustment. In order to determine on which variables men and women responded differently, univarite $F$ statistics were calculated. Women and men were found to differ on the LSS $[F(1,167)=5.06, p<.05]$ and the Institutional Attachment $[F(1,167)=11.14, p<.01]$ and Personal-Emotional subscales 
$[F(1,167)=4.13, p<.05]$ of the SACQ. Women were more likely to endorse symptoms on the LSS than were men, indicating the participating men reported being better adjusted than the women with regard to broad psychological symptoms. Women also reported being less well-adjusted than men on the personal-emotional scale of the SACQ. Finally, female participants reported a greater attachment to the institution than did men. The means and standard deviations obtained for both men and women on the different measures and their subscales are presented in Table 1 .

Based on the finding of significant sex differences in adjustment, parenting style, and satisfaction with college measures, subsequent analyses were computed separately for men and women. The mean scores for the different scales of the SACQ and NEO-FFI were found to be comparable to those reported in the SACQ (Baker \& Siryk, 1999) and NEO-PI-R manuals (Costa \& McCrae, 1992), respectively. In addition, the PAQ mean scores were akin to those reported by Buri (1991), and the SWLS mean scores were similar to those reported by Diener et al. (1985).

\section{Correlations}

In order to investigate the relationships among personality traits and adjustment, perceived parenting styles and adjustment, and perceived parenting styles and personality traits, correlations between variables were calculated. The correlations for parenting style and personality with adjustment variables are presented for both women (Table 2) and men (Table 3).

Correlations between perceived parenting style and adjustment revealed some significant associations, ranging between $r$ $=.20$ and .31 for women and $r=.21$ and .34 for men. For both men and women, paternal permissiveness was negatively correlated with adjustment variables, and paternal authoritativeness was positively correlated with adjustment. Paternal permissiveness was associated with poorer adjustment for women on the LSS $(r=.20)$, SWLS ( $r=-.31)$, Social Adjustment subscale $(r=-.26)$, and the SACQ Full Scale $(r=-.22)$. For men, paternal permissiveness was similarly associated with the Social Adjustment subscale $(r=-.25)$ and the SACQ Full Scale $(r$ $=-.32)$, but also with the Academic Adjustment $(r=-.21)$ and Institutional Attachment ( $r=-.34)$ subscales.

For women, authoritarian maternal parenting was associated with 5 of the 7 adjustment variables $(r=-.22$ to -.28$)$ revealing that maternal authoritarian parenting was associated with poorer adjustment. For men, however, maternal authoritarian parenting was not significantly correlated with any adjustment variables. Instead, for men, perceived maternal authoritative parenting was associated with positive adjustment $(r=.28$

Table 1.

Means and standard deviations.

\begin{tabular}{|c|c|c|c|c|}
\hline & \multicolumn{2}{|c|}{ Men } & \multicolumn{2}{|c|}{ Women } \\
\hline & $M$ & $S D$ & $M$ & $S D$ \\
\hline Maternal Authoritarian & 29.74 & 4.37 & 28.62 & 5.04 \\
\hline Maternal Authoritative & 33.69 & 4.45 & 34.35 & 4.49 \\
\hline Maternal Permissive & 26.57 & 4.64 & 24.74 & 4.22 \\
\hline Paternal Authoritarian & 32.33 & 5.15 & 31.00 & 6.28 \\
\hline Paternal Authoritative & 33.97 & 5.34 & 33.51 & 7.09 \\
\hline Paternal Permissive & 25.96 & 5.56 & 24.10 & 5.25 \\
\hline Neuroticism & 54.86 & 9.53 & 54.06 & 10.07 \\
\hline Extraversion & 56.70 & 9.41 & 57.96 & 9.74 \\
\hline Openness to Experience & 47.27 & 9.67 & 49.79 & 9.64 \\
\hline Agreeableness & 43.65 & 10.99 & 47.95 & 11.70 \\
\hline Conscientiousness & 39.74 & 8.28 & 41.59 & 9.95 \\
\hline LSS & 3.12 & 2.77 & 4.27 & 3.41 \\
\hline SWLS & 25.07 & 5.25 & 25.29 & 5.91 \\
\hline SACQ Academic & 135.64 & 22.58 & 141.09 & 26.17 \\
\hline SACQ Social & 121.90 & 22.37 & 128.14 & 28.20 \\
\hline SACQ Personal-Emotional & 86.42 & 18.41 & 79.85 & 22.09 \\
\hline SACQ Institutional Attachment & 96.43 & 19.60 & 106.81 & 20.04 \\
\hline SACQ Full Scale & 399.29 & 57.04 & 409.47 & 68.00 \\
\hline
\end{tabular}

Note: scores in bold reflect significant differences at $p<.05$ level. 
Table 2.

Parenting style and personality correlations with adjustment variables for women.

\begin{tabular}{|c|c|c|c|c|c|c|c|}
\hline Variable & LSS & SWLS & Acad & Soc & Atta & P-E & FS \\
\hline \multicolumn{8}{|l|}{ Parenting Style } \\
\hline M Authoritarian & $.27 * *$ & -.16 & $-.28 * *$ & $-.22 *$ & $-.23 *$ & -.19 & $-.28 * *$ \\
\hline M Authoritative & -.10 & $.22 *$ & .08 & .04 & .07 & .10 & .08 \\
\hline M Permissive & .17 & -.04 & -.16 & -.04 & -.10 & $-.21 *$ & -.17 \\
\hline P Authoritarian & .16 & -.12 & -.12 & .10 & .08 & -.10 & -.04 \\
\hline P Authoritative & $-.19 *$ & .18 & .10 & $.20^{*}$ & .13 & .11 & .17 \\
\hline P Permissive & $.20^{*}$ & $-.31 * *$ & $-.26 * *$ & -.14 & -.20 & -.13 & $-.22 *$ \\
\hline \multicolumn{8}{|l|}{ Personality } \\
\hline Neuroticism & $.66^{* *}$ & $-.59 * *$ & $-.40 * *$ & $-.33 * *$ & $-.34 * *$ & $-.65^{* *}$ & $-.56^{* *}$ \\
\hline Extraversion & $-.34 * *$ & $.51^{* *}$ & .03 & $.39^{* *}$ & $.42 * *$ & .14 & $.26^{* *}$ \\
\hline Openness & -.01 & -.05 & .14 & .05 & .04 & .08 & .11 \\
\hline Agreeableness & $-.43 * *$ & $.40 * *$ & .17 & $.34 * *$ & $.37 * *$ & $.28^{* *}$ & $.34 * *$ \\
\hline Conscientiousness & $-.31 * *$ & $.27 *$ & $.51^{* *}$ & .09 & .15 & $.21 *$ & $.33 * *$ \\
\hline
\end{tabular}

Note: $*$ correlation is significant at the $p<.05$ level; **correlation is significant at the $p<.01$ level. Acad $=$ Academic Adjustment, Soc $=$ Social Adjustment, Atta $=$ Attachment to the Institution, $\mathrm{P}-\mathrm{E}=$ Personal-Emotional Adjustment, FS = SACQ Full Scale, $\mathrm{M}=$ Maternal, $\mathrm{P}=$ Paternal.

Table 3.

Parenting style and personality correlations with adjustment variables for men.

\begin{tabular}{|c|c|c|c|c|c|c|c|}
\hline Variable & LSS & SWLS & Acad & Soc & Atta & P-E & FS \\
\hline \multicolumn{8}{|l|}{ Parenting Style } \\
\hline M Authoritarian & .10 & -.22 & -.16 & -.06 & -.14 & -.07 & -.16 \\
\hline M Authoritative & -.16 & $.28 *$ & .17 & $.34 * *$ & $.34 * *$ & .17 & $.31 * *$ \\
\hline M Permissive & .08 & -.03 & -.11 & .07 & .01 & -.04 & -.05 \\
\hline P Authoritarian & -.02 & $.24 *$ & .05 & .12 & .16 & -.02 & .08 \\
\hline P Authoritative & -.01 & $.24 *$ & .23 & $.35^{*}$ & $.31 *$ & -.03 & $.26^{*}$ \\
\hline P Permissive & .05 & -.02 & $-.21 * *$ & $-.25^{*}$ & $-.34 * *$ & -.18 & $-.32 * *$ \\
\hline \multicolumn{8}{|l|}{ Personality } \\
\hline Neuroticism & $.72 * *$ & $-.47^{* *}$ & $-.48 * *$ & $-.24 * *$ & $-.29 * *$ & $-.74 * *$ & $-.59 * *$ \\
\hline Extraversion & -.09 & .16 & .20 & $.38^{* *}$ & $.39^{* *}$ & $.33^{* *}$ & $.41^{* *}$ \\
\hline Openness & .13 & .17 & .14 & .23 & .10 & .07 & .19 \\
\hline Agreeableness & $-.29 * *$ & $.39^{* *}$ & $.43^{* *}$ & .17 & $.28 *$ & $.30^{*}$ & $.40^{* *}$ \\
\hline Conscientiousness & -.16 & $.29 *$ & $.60^{* *}$ & .05 & .19 & $.30^{* *}$ & $.41^{* *}$ \\
\hline
\end{tabular}

Note: $*$ correlation is significant at the $p<.05$ level; $* *$ correlation is significant at the $p<.01$ level. Acad $=$ Academic Adjustment, Soc $=$ Social Adjustment, Atta $=$ Attachment to the Institution, $\mathrm{P}-\mathrm{E}=$ Personal-Emotional Adjustment, $\mathrm{FS}=\mathrm{SACQ}$ Full Scale, $\mathrm{M}=$ Maternal, $\mathrm{P}=\mathrm{Paternal}$.

to .34) for 4 of the 7 adjustment variables. For women, maternal authoritative parenting was only correlated with the SWLS. In addition, maternal permissive parenting was only associated with one adjustment variable (Personal-Emotional Adjustment, $r=-.21$ ) for women and none for men, and paternal authoritarian parenting was only associated with one adjustment variable for men (SWLS, $r=.24$ ) and none for women. Though only associated with one variable, it is notable that paternal authori- 
tarian parenting was positively correlated with the SWLS for men.

Although significant relationships were found between perceived parenting style and adjustment, the magnitude of the relationships was typically low $(r=.20$ to .34$)$. Personality variables were found to be more related to adjustment variables than the parenting style variables were. For both men and women, Neuroticism was related to all adjustment variables (ranging from -.24 to -.74 ), with each association indicating poor adjustment. Neuroticism was most strongly associated with poor adjustment on the LSS and the Personal-Emotional Adjustment subscale for women ( $r=.66$ and -.65 , respectively) and men $(r=.72$ and -.74 , respectively).

Extraversion, Agreeableness, and Conscientiousness were all associated with positive adjustment for both men and women, though some variation was noted regarding which adjustment variables were significantly associated with personality traits when comparing men and women. For example, for women, Extraversion was associated with positive adjustment $(r=.26$ to .51) as measured by the LSS, SWLS, Social Adjustment subscale, Institutional Attachment subscale, and the SACQ Full Scale. For men, Extraversion was related to all of the SACQ subscales except for Academic Adjustment ( $r=.33$ to .41) but not associated with the LSS or the SWLS. Agreeableness was found to be related to every adjustment variable for women ( $r$ $=.28$ to -.43 ) except for Academic Adjustment, and every variable for men ( $r=.28$ to .43 ) except Social Adjustment. Conscientiousness was strongly correlated with the Academic Adjustment subscale for both women $(r=.51)$ and men $(r$ $=.60$ ), and was related to the remaining adjustment variables $(r$ $=.27$ to .41$)$ with the exceptions of the Social Adjustment and Institutional Attachment subscales for both men and women. Openness to Experience was not associated with any of the adjustment variables for either men or women.

Correlations were also calculated between parenting style and personality. Analyses revealed a minimal number of significant correlations. For men, Agreeableness was correlated with maternal authoritative parenting $(r=39)$ and paternal permissiveness $(r=-.34)$. For women, paternal authoritative parenting and Neuroticism were correlated at $r=-.19$, maternal authoritative parenting was associated with Extraversion $(r$ $=.27)$ and Conscientiousness $(r=.21)$, and paternal permissiveness and Agreeableness were correlated at $r=-.22$. Perceived parenting style was not found to be associated with many personality traits for freshmen students, and the magnitude of the significant relationships was typically in the low range $(r=-.19$ to .39$)$.

\section{Multiple Mediation Analyses}

In order to test for the presence of mediators in the predictive relationships between parenting style and adjustment variables, a series of multiple mediation analyses (Preacher \& Hayes, 2008) were run using the causal steps strategy as outlined by Baron and Kenny (1986). Separate analyses were run for men and women, yielding a total of 84 analyses. While most of the models did not reach significance, there were two models that yielded full mediators, one model that yielded a partial mediator, and several models that were trending toward mediation. Almost all of the significant models pertained to women, with only one model that was trending toward significance for male students. Despite the significant findings, given the large number of models that were investigated for mediation, the significant models found were likely due to chance. When a Bonferroni correction is applied, then the findings are no longer significant. These findings indicate that, overall, broad personality traits did not mediate the relationships between perceived parenting and adjustment for college students.

\section{Discussion}

The purpose of the present study was to systematically investigate the relationships between parenting style, personality traits, positive and negative psychological adjustment, and adjustment to college. Analyses revealed that relationships exist between and among personality, perceived parenting style, and the adjustment that freshmen students make to college. These relationships were found to be different with regard to gender.

The first goal of the study was to determine if perceived parenting style was related to adjustment as reported by college freshmen in their first semester of school. Perceived parenting style was found to be associated with different adjustment variables, for example, permissive parenting was correlated with negative adjustment and authoritative parenting was correlated with positive adjustment. Despite the statistically significant relationships between parenting style and adjustment, the magnitude of the relationships were generally found to be low and not clinically meaningful. However, these results do affirm the literature that authoritative parenting is beneficial.

A second goal of the study was to assess if personality traits were related to adjustment variables. Numerous statistically significant differences were found in relationships between personality traits and aspects of adjustment for college students. The magnitudes of the relationships were found to be robust and clinically meaningful. For instance, poor academic performance was found to be related to low levels of Conscientiousness. It is believed that administrators can make fairly good predictions about different aspects of adjustment to college based on students' personality traits. The present study also confirmed previous findings, such that Neuroticism is linked to poorer adjustment and Extraversion is related to positive adjustment (Bardi \& Ryff, 2007).

A third goal of the study was to determine if perceived parenting styles were related to the personality traits of college freshmen. Overall, there were very few significant correlations between perceived parenting style and personality traits for either men or women, indicating that there is not likely a strong relationship between freshmen students' perceptions of the parenting they received and their own personality traits. The relationships that were found to be significant were different for men and women and of a low magnitude.

The final goal of the present study was to determine if the relationships that were found between perceived parenting style and student adjustment were mediated by personality traits. Analyses revealed that, for most of the proposed mediation models, personality traits were not found to mediate the relationships between perceived parenting and adjustment. Overall, it appears that the mechanism by which parenting is related to adjustment and adaptation to college is largely not due to personality traits. There are several possible explanations for why personality was not found to mediate the relationships between 
parenting and measures of adjustment. It is possible that the relationships between these constructs were not strong enough to carry these models, given the stronger relationships between personality and adjustment than between parenting and adjustment, and the very minimal relationships found between parenting styles and personality. It is notable that for both men and women, there were very few significant relationships between perceived parenting and personality traits, which are criteria that must be met in order to conduct mediational analyses.

The current study affirmed previous results that authoritative parenting is related to positive adjustment. However, it is to be noted that the magnitude of this relationship is low and, consequently, would not likely be a good predictor of positive adjustment. In addition, the results of the current study confirmed previous findings with respect to Neuroticism being linked to negative adjustment and Extraversion to positive adjustment. In terms of adjustment to college, the relationship between Neuroticism and poor college adjustment is strong and, consequently, a good predictor. In contrast, the relationship between Extraversion and positive adjustment to college was not found to be particularly significant for men, and the magnitude of the relationships for women was rather small. Therefore, Extraversion may not be a good predictor of positive college adjustment.

Given the correlations between perceived parenting and adjustment, personality traits and adjustment, and perceived parenting and personality, it appears that the strongest correlations are between students' self-reported personality traits and adjustment. College administrators might choose to screen incoming freshmen to identify those students who are at greatest risk for poor adjustment to college. After identification the students who may be at the greatest risk (those who have high levels of Neuroticism and low levels of Extraversion, Agreeableness, and Conscientiousness), administrators may consider providing preventative assistance to the identified students. For example, it may be important to ensure that students who are identified as "at risk" have meetings scheduled with school advisors/counselors throughout the first semester of college. Identified students may also benefit from attending seminars that focus on appropriate ways to cope with difficult times in their classes as well as tips for maintaining organization and keeping up with classes. Such assistance could facilitate retention and prevent students from withdrawing from college.

Another implication of the present study is that, methodologically, it is important to separate men and women when investigating these constructs. Based on the findings of the current and past (Wintre \& Sugar, 2000) studies, differential relationships exist for men and women among the constructs of parenting, personality, and adjustment. Given these findings, it seems important to separate analyses by gender when investigating these constructs as combining them could lead to very different interpretations of these relationships.

\section{Strengths and Limitations}

With regard to strengths and limitations, the most significant limitation of the study is that it relied exclusively on student self-report. Despite that limitation, the results of the study were found to be congruent with those previously reported in the literature, which might mitigate reliance student self-report. In addition, the sample may be seen as both a strength and a limitation. The sample is a limitation as the participants were from a Midwest, religiously-affiliated university, and generally from families of a high socioeconomic status, which may limit the generalizability of the findings. Furthermore, because differences were found between men and women, and were therefore analyzed separately, the size of the sample was relatively small. However, once again, the results were congruent with what has been reported in the literature thus far. The sample is a strength in that it consisted of true freshmen attending a four-year accredited university with most students living away from home for the first time, which is rather representative of universities across the country where students have the option of living in university housing. Finally, a strength of the study is its utilization of psychometrically-sound instruments in terms of their reliability and validity.

\section{Future Directions}

Future studies could investigate the different styles employed by parents in a two-parent home to determine if certain parenting styles most often co-occur, and then how those parenting combinations predict adjustment. While it has been reported that most parents within a household utilize similar parenting styles (Simons \& Conger, 2007), it would be interesting to investigate the perceptions of college students in regard to the similarity of their parents' styles, and how these combinations may relate to students' personality traits and adjustment to college. Future studies could also investigate the possibility of moderators among parenting style, personality, and adjustment. It is possible that personality may impact the strengths of the relationships between parenting and adjustment, instead of acting as the mechanism by which parenting affects adjustment. A similar study could also be conducted with a younger sample, such as with high school freshmen who still reside with their parents, to investigate the impact of living with parents versus living away from home, as the majority of this sample did.

\section{References}

Baker, R. W. \& Syrik, B. (1999). Student adaptation to college questionnaire (SACQ) manual. Los Angeles, CA: Western Psychological Services.

Baldwin, D. R., McIntyre, A., \& Hardaway, E. (2007). Perceived parenting styles on college students' optimism. College Student Journal, 41, 50-557.

Bardi, A., \& Ryff, C. D. (2007). Interactive effects of traits on adjustment to a life transition. Journal of Personality, 75, 955-984. doi:10.1111/j.1467-6494.2007.00462.x

Baron, R. M., \& Kenny, D. A. (1986). The moderator-mediator variable distinction in social psychological research: Conceptual, strategic, and statistical considerations. Journal of Personality \& Social Psychology, 51, 1173-1182. doi:10.1037/0022-3514.51.6.1173

Baumrind, D. (1968). Authoritarian vs authoritative parental control. Adolescence, 3, 255-272.

Buri, J. R. (1991). Parental authority questionnaire. Journal of Personality Assessment, 57, 110-119. doi:10.1207/s15327752jpa5701_13

Costa, P. T. Jr., \& McCrae, R. R. (1980). Influence of extraversion and neuroticism on subjective well-being: Happy and unhappy people. Journal of Personality and Social Psychology, 38, 668-678. doi: $10.1037 / 0022-3514.38 .4 .668$

Costa, P. T. Jr., \& McCrae, R. R. (1992). NEO PI-R professional man- 
ual. Odessa, FL: Psychological Assessment Resources.

Dahmus, S., \& Bernardin, H. J. (1992). Student adaptation to college questionnaire. Measurement \& Evaluation in Counseling \& Development, 25(3), 139-142.

DeNeve, K. M., \& Cooper, H. (1998). The happy personality: A meta-analysis of 137 personality traits and subjective well-being. Psychological Bulletin, 124, 197-229. doi:10.1037/0033-2909.124.2.197

Diener, E., Emmons, R. A., Larsen, R. J., \& Griffin, S. (1985). The Satisfaction with Life Scale. Journal of Personality Assessment, 49, 71-75. doi:10.1207/s15327752jpa4901 13

Heaven, P. C. L, \& Ciarrochi, J. (2008). Parental styles, conscientiousness, and academic performance in high school: A three-wave longitudinal study. Personality and Social Psychology Bulletin, 34, 451-461. doi:10.1177/0146167207311909

Hickman, G. P., Bartholomae, S., \& McKenry, P. C. (2000). Influence of parenting styles on the adjustment and academic achievement of traditional college freshmen. Journal of College Student Development, 41, 41-54.

Lamborn, S. D., Mounts, N. S., Steinberg, L., \& Dornbusch, S. M. (1991). Patterns of competence and adjustment among adolescents from authoritative, authoritarian, indulgent, and neglectful families. Child Development, 62, 1049-1065. doi:10.2307/1131151

Langner, T. S. (1962). A twenty-two item screening score of psychiatric symptoms indicating impairment. Journal of Health and Human Behavior, 6, 269-276. doi:10.2307/2948599

Milevsky, A., Schlechter, M., \& Netter, S. (2007). Maternal and paternal parenting styles in adolescents: Associations with self-esteem, depression and life-satisfaction. Journal of Child and Family Studies, 16, 39-47. doi:10.1007/s10826-006-9066-5

National Center for Education Statistics. (2003). URL (20 April 2008) http://nces.ed.gov/programs/coe/2003/section3/indicator20.asp

Preacher, K. J., \& Hayes, A. F. (2008). Asymptomatic and resampling strategies for assessing and comparing indirect effects in multiple mediator models. Behavior Research Methods, 40, 879-891. doi:10.3758/BRM.40.3.879

Simons, L. G, \& Conger, R. D. (2007). Linking mother-father differences in parenting to a typology of family parenting styles and adolescentoutcomes. Journal of Family Issues, 28, 212-241. doi: $10.1177 / 0192513 X 06294593$

Slicker, E. K., \& Thornberry, I. (2002). Older adolescent well-being and authoritative parenting. Adolescent \& Family Health, 3, 9-19.

Toews, M. L., \& Yazedjian, A. (2007). College adjustment among freshmen: Predictors for White and Hispanic men and women. College Student Journal, 41, 891-900.

Wagerman, S. A., \& Funder, D. C. (2007). Acquaintance reports of personality and academic achievement: A case for conscientiousness. Journal of Research in Personality, 41, 221-229. doi:10.1016/j.jrp.2006.03.001

Wintre, M. G., \& Sugar, L. A. (2000). Relationships with parents, personality, and the university transition. Journal of College Student Development, 41, 202-214.

Zyphur, M. J., Bradley, J. C., Landis, R. S., \& Thoresen, C. J. (2008). The effects of cognitive ability and conscientiousness on performance over time: A censored latent growth model. Human Performance, 21, 1-27. doi:10.1080/08959280701521967 